\title{
METHODOLOGICAL ISSUES IN TESTING THE MARGINAL PRODUCTIVITY THEORY
}

BY

\author{
PETER T. GOTTSCHALK* AND JAN TINBERGEN**
}

\section{INTRODUCTORY}

Several attempts have been made to verify the marginal productivity theory of distribution. None of the recent attempts have given results which are consistent with the theory. In this note we show how the evolution of these studies reflects an attempt to deal with a fundamental methodological problem. The essence of all tests is to assume a functional form and level of aggregation of the factor inputs into a production function, estimate the function at the appropriate level of aggregation, and compare the resulting marginal products with the observed factor payments. Therefore, by necessity, all tests of the distribution theory are intimately linked to tests of the production theory. If estimated marginal productivities are not equal to factor payments, one can only conclude that the distribution theory or the production assumptions are wrong. A door is always left open to salvage either theory. This is the fundamental methodological problem.

The only practical way of dealing with this dilemma is to agree on a fair test of the theory before the test is run. This is essential if the marginal productivity theory is to satisfy the criterion that a theory must be refutable. In this paper we offer the outlines of such a test so that it may be known and discussed before the test is performed.

The paper is divided into five sections. Section 1 introduces our problem. Section 2 reviews recent attempts to take account of criticisms of previous tests. Section 3 reviews a method developed for dealing with the problem of multicollinearity which arises when several labour categories are introduced into the production function. We offer a qualification to this method and review some evidence which indicates that the qualitative results are not

* Bowdoin College, Brunswick and Institute for Research on Poverty, University of Wisconsin, Madison.

** Erasmus University, Rotterdam, The Netherlands. 
altered by this correction. Section 4 presents the methodology for what we would consider to be a fair test of the marginal productivity theory. Section 5 suggests that as a practical matter the rejection of the marginal productivity theory would not cause great harm to applied economics. In many cases it is a superfluous assumption; not always, though.

\section{REVIEW OF CRITICISMS OF PAST TESTS}

Previous tests of the theory can be criticized on four grounds. (1) The functional forms used were overly restrictive in their assumptions about the elasticities of substitution. (2) The inputs were too highly aggregated. Specifically, heterogeneous labour was grouped into only one or two labour inputs. (3) The use of state or industry data caused observation aggregation bias. (4) A distinction should be made between short-term and long-term variations. The history of attempts to test the theory can be viewed as an evolution to deal with each of these legitimate problems.

In this article we will not deal with issue (4), but restrict ourselves to referal to an interesting attempt by Kuipers (1974) to deal with this aspect, considering long-term functions as envelops of short-term functions.

Douglas (1934), using highly aggregated data, thought that he had found confirming evidence for the theory. Factor shares predicted by a two factor Cobb-Douglas function (which assumes unitary elasticity of substitution) closely matched the shares received by capital and labour. This confirming evidence was, however, called into question when Thurow (1968), using aggregate time series data, and Hildebrand and Liu (1965), using a crosssection of states, found that with better data the marginal products did not match the factor payments. Capital seemed to receive more than its marginal product and labour less.

One possible explanation for these negative results is that by using one labour aggregate the authors implicitly assumed that all workers were equally productive, e.g. the labour input increased by the same amount whether a craftsman or operative was added. Gottschalk (1978) and Tinbergen and Kol (1980), independently introduced several different labour categories into a Cobb-Douglas function to take account of this possibility. Tinbergen and Kol estimated economy wide functions for the USA and Japan, using states as the units of observation for the former and prefectures for the latter. Gottschalk estimated a function for U.S. manufacturing, using two digit industries and states as observations. The two studies rejected the distribution theory. Both indicated that managers received more than their marginal products 
(see Section 5 of this paper for a possible explanation). Tinbergen and Kol also showed blue collar workers and farmers receiving more than their marginal product.

Our increased understanding of less restrictive forms, such as the CES or translog (TL) production function, offer another potential explanation of why the theory has been rejected by the previously mentioned studies. It is possible that by allowing the elasticity of substitution between all pairs of inputs to be any constant (CES) or to impose even weaker restrictions (TL) would yield nonrejection of the distribution theory. The problem with estimating either of these functions is that they either are nonlinear (CES) or involve a large number of cross products (TL). For this reason most authors have assumed the marginal productivity condition by regressing factor payments against the derivative of the production function, which contains many fewer variables. This methodology is clearly unacceptable for our purposes. ${ }^{1}$

Appelbaum (1974) is the only author who explicitly works with a TL to test the distribution theory. Because of possible multicollinearity he includes only three inputs (capital, production and nonproduction workers) in his study, using aggregate time series data. His work, which reflects recent developments in production function estimation and duality theory, strongly rejects the neoclassical model, though once again it is impossible to determine whether this is caused by factor payments diverging from marginal productivities or by other problems, such as aggregation bias (also mentioned by Appelbaum).

Thus we see that two out of the three potential criticisms (aggregation of inputs and restrictive functional form specification) have been explored in previous research, though studies have not dealt with the two problems simultaneously. No attempt has, however, been made to test the theory with firm level data to counter the charge of observation aggregation bias. In the next section we review the method originally suggested in Gottschalk (1978) to deal with the multicollinearity caused by entering many inputs into a production function. We show that an additional assumption is necessary to apply this technique to aggregate data, suggesting that it may be more appropriately used with firm level data.

1 Note that the same methodological problem confronts the estimation of elasticities of substitution using this method. Suppose that the null hypothesis is that $\sigma=1$. A study which estimates a TL assuming the marginal productivity condition may yield a $\sigma$ not equal to 1 either because $\sigma$ is indeed not 1 or because the marginal productivity condition does not hold. 
Entering many inputs, even in a Cobb-Douglas function, causes serious problems of multicollinearity. Gottschalk (1978) suggested an alternative specification of the production function which would reduce collinearity. He based his specification on the recognition that production can often be viewed as a series of processes which must all be completed in order to obtain final production. In many cases this concept is appropriate for a more realistic and concrete description of the production process. Gottschalk gives an example of shaping and painting. He might have added transportation and administration. In addition to Gottschalk's example one might mention the textile industry: a succession of spinning, weaving and finishing, accompanied by administration. A number of examples, at the firm level, are given by Boon $(1964,1978,1980,1981)$ and by Griliches and Ringstad (1971). This implies that it may be possible to model production as a set of interrelated process equations. Successive subprocesses may be modeled in different ways: the first process' output may be taken as one of the inputs to the next process. Much depends on what data are available. If each process only uses a subset of all occupations, then each equation can be estimated with a smaller number of independent variables. Gottschalk shows that, in order to calculate marginal products, each equation must contain some inputs which are also used in the other process(es), called common factors, and others which are only used in one process, called specific factors.

We now show that if one cannot obtain separate measures of the amount of the common factor used in each process then all factors enter into each equation. Having derived this theoretical result we then turn to Gottschalk's original application and to the need for firm level data for a more definitive test.

Using mainly Gottschalk's notation production $V$ will be measured by two functions

$$
\begin{aligned}
& V=S\left(J_{1}, M_{1}, \ldots, M_{H}\right) \\
& V=P\left(J_{2}, N_{1}, \ldots, N_{K}\right)
\end{aligned} \quad \text { The 'process equations" }
$$

Letting lower case letters represent differentials,

$$
\begin{aligned}
& v=f_{\mathrm{o}}{ }^{1} j_{1}+m \\
& v=f_{\mathrm{o}}{ }^{2} j_{2}+n
\end{aligned}
$$


whereas

$$
j_{1}+j_{2}=j
$$

where

$$
m=f_{1}^{1} m_{1}+f_{2}^{1} m_{2}+f_{3}^{1} m_{3}+\ldots f_{H}^{1} m_{H}=\Sigma f_{h}^{1} m_{h}
$$

and

$$
n=f_{1}^{2} n_{1}+f_{2}^{2} n_{2}+f_{3}^{2} n_{3}+\ldots f_{K}^{2} n_{K}=\Sigma f_{k}^{2} n_{k}
$$

Here $j$ is the common factor, of which $j_{1}$ is used in $S$ and $j_{2}$ in $P ; m_{1} \ldots m_{H}$ and $n_{1} \ldots n_{K}$ are the factors specific to $S$ and $P$ and the $f$ s are partial derivatives. The upper index of the $f$ is 1 for $S$ and 2 for $P$; the lower index is 0 for the $j$, and identical to the lower indices of the $m$ and $n$. The symbols $m$ and $n$ without index stand for the total impact of all $m_{h}$ and $n_{k}$. Equations (1) through (5) constitute the essence of Gottschalk's theory. We now turn to the problem of estimating the coefficients appearing in that theory.

If $M, N, J_{1}$ and $J_{2}$ were observable one could estimate equations (1) and (2) directly. Suppose, however, that only observations on $M_{h}, N_{k}$ and $J$ are available. Equations $\left(1^{\prime}\right),\left(2^{\prime}\right)$ and (3) can now be used to rewrite $v$ in terms of observables. Writing

$$
b_{r}=1 / f_{o}^{r} \quad(r=1,2)
$$

$\left(1^{\prime}\right)$ and $\left(2^{\prime}\right)$ can be written:

$$
\begin{aligned}
& j_{1}=b_{1}\left(v-\Sigma f_{h}^{1} m_{h}\right) \\
& j_{2}=b_{2}\left(v-\Sigma f_{k}^{2} n_{k}\right)
\end{aligned}
$$

and

$$
j=j_{1}+j_{2}=\left(b_{1}+b_{2}\right) v-b_{1} \Sigma f_{h}^{1} m_{h}-b_{2} \Sigma f_{k}^{2} n_{k}
$$

Finally, with

$$
b_{1}+b_{2}=b
$$


we find:

$$
v=\left(j+b_{1} \Sigma f_{h}^{1} m_{h}+b_{2} \Sigma f_{k}^{2} n_{k}\right) / b
$$

and:

$$
\begin{aligned}
& j_{1}=\left(b_{1} j-b_{1} b_{2} \Sigma f_{h}^{1} m_{h}+b_{1} b_{2} \Sigma f_{k}^{2} n_{k}\right) / b \\
& j_{2}=\left(b_{2} j+b_{1} b_{2} \Sigma f_{h}^{1} m_{h}-b_{1} b_{2} \Sigma f_{k}^{2} n_{k}\right) / b
\end{aligned}
$$

The last two equations show that the econometric estimation of equations (1) and (2) cannot be undertaken as a multiple regression of $V$ on $J$ and $M$ or on $J$ and $N$, respectively, since both $J_{1}$ and $J_{2}$ depend on $J, M$ and $N$.

Since Gottschalk's aggregate data could not separate $J$ into $J_{1}$ and $J_{2}$, he entered $J$ as a proxy for $J_{1}$ and $J_{2}$. The consequence of this procedure can be seen by writing

$$
J_{1}=\Phi J
$$

where capital letters are absolute values and $\Phi$ is the proportion of $J$ used in Process 1. Hence

$$
j_{1}=\bar{J} \varphi+\bar{\Phi} j
$$

where barred symbols represent average absolute values. Entering $j$ instead of $j_{1}$ is equivalent to having $\varphi$ as a missing variable. If the deviation from average is either constant across observations or varies randomly, then all the coefficients are unbiased estimates. If, however, $\varphi$ is not independent of $m, n$ or $j$, then its exclusion will cause bias.

Tinbergen (1980) offers a method for dealing with this potential bias by introducing two additional descriptive equations. He then solves the system of equations for the parameters of the production function. His results indicate that Gottschalk's findings are not altered substantially by this correction. ${ }^{2}$ He then applies the same method to the data in Tinbergen and Kol (1980) to reduce the effect of multicollinearity. Their findings are also substantially confirmed.

While Tinbergen offers a method for using Gottschalk's technique with aggregate data, the best application would be to firm level data, where one could directly observe $j_{1}$ and $j_{2}$. For this and the reasons discussed in Section

2 Recently, Tinbergen undertook a generalization of this method, to be published elsewhere, which does not impair either of the conclusions of his first method. 
2 we turn to a proposed test of the marginal productivity theory using firm level data.

\section{A FAIR TEST?}

We suggest that a fair test would contain the following elements. The function should be estimated with firm level data, using several labour inputs and a functional form sufficiently general to allow for a wide range of elasticities of substitution.

Using disaggregated data would accomplish three objectives. First, we would minimize the problems of observation aggregation bias by testing the theory at the level of aggregation for which it was designed. Second, by picking a firm for which the multiprocess model is applicable, such as a textile firm, we could more confidently use this technique to include a larger number of inputs. Finally, by directly measuring $j_{1}$ and $j_{2}$, we could avoid the potential bias described in Section 3.

The drawback of firm specific data is of course that the behavior of one firm may not represent the behavior of other firms. There are, however, two methodological principles which should be kept in mind before rejecting conclusions based on firm level data. First, theories should be general. In fact, the theory of the firm is developed in very general terms (all cost minimizing firms, whether they profit maximize or not, are assumed to have marginal revenue products proportional to factor payments). Without a theory to tell us which firms are not covered by the theory we must assume that all firms are covered. To do otherwise is to make the theory useless. We would never know when it should be applied. The second methodological principle is that theories should be refutable. If firm level data are unacceptable because they are not representative and if aggregate data are unacceptable because they cause bias, then there seems to be no way of testing the theory. At best it becomes a useful tautology.

\section{IS THE MARGINAL PRODUCTIVITY THEORY NECESSARY?}

Suppose that support is not found for the theory. Would this seriously reduce our ability to carry out quantitative research? We do not believe so. In almost all applied work the marginal productivity assumption is not necessary to reach policy relevant conclusions. We offer four examples to illustrate. 
First, consider the normative premise that factors should be paid according to their contribution to society. As many others have pointed out there are many other criteria for determining what is just ${ }^{3}$ but, for the moment, consider that this is what an incomes policy board has decided to use as a normative criterion. Would the board be concerned with individual marginal revenue products? Tinbergen has developed elsewhere (1981) the concept of counterproductivity which suggests that marginal revenue products may not be a useful concept for setting the wages of certain types of labour. Counterproductivity is the phenomenon that it is some individuals' task to partly or wholly destroy somebody else's product. For instance, it is a surgeon's task to annihilate the effect traffic caused in a traffic accident. Or it is a dentist's task to counteract the tooth damage caused by sweets consumption.

Most pronounced is the counterproductivity that characterizes the task of the 'carriers of competition.' Sales managers and other sales workers of Firm A supposed to compete with Firm B are in charge of annihilating part of the effort of the latter firm's sales workers. If they succeed in performing their tasks, the total productivity of all the sales workers of firms A and B is small. The same applies to their marginal productivity.

Does this mean that these workers should be paid almost no income? Not at all: their social function is to maintain a competitive system, which produces significantly more than a monopolistic system, where all product groups are monopolized. The joint utility of all carriers of competition consists of the utility of the additional goods and services produced in the competitive system, compared with the monopolized system. ${ }^{4}$ The production (and its social utility) of a 'world of monopolies' (Joan Robinson's phrase) has to be estimated in order to arrive at a figure of 'just incomes' in the sense quoted above. Anyway, earnings of the 'carriers of competition' cannot reasonably be put equal to their marginal productivity.

Second, consider the estimation of elasticities of substitution. The research in this important field, which has been summarized in an excellent fashion by Hamermesh and Grant (1980) and Hamermesh (1976), almost always assumes the marginal productivity condition. It is, however, important to make the distinction between the technological elasticity of substitution, which relates changes in factor proportions to changes in relative marginal physical products,

3 The question whether other criteria of equity are preferable - as suggested by Tinbergen - will not be taken up here.

4 Littlechild (1981) rightly argues that Harberger's and Cowling and Mueller's estimates of monopoly profits do not measure such profits. The fact that these amounts are of the order of one per mille and one percent respectively of national income rather show that the countries considered were very close to competitive economies. 
and what we will call the market elasticity of substitution, which relates changes in relative factor proportions to changes in relative factor prices. It is the latter which is policy relevant and it can be measured. ${ }^{5}$ One does not need to assume the marginal productivity condition in order to estimate this important policy parameter. It is easy to show the relationship between the technological substitution parameter $\sigma$ and the market parameter $\sigma_{m}$. Suppose that because of discrimination, disequilibrium, or any number of other factors wages are not equal to marginal products. For the $i$ th labour group let $W_{i}$ be the wage, $X_{i}$ the input, $F_{i}$ be its marginal physical product, and $b_{i}$ be the ratio of the wage to the marginal product. By definition:

$$
w_{i}=b_{i} F_{i}
$$

The measured elasticity of substitution $\sigma_{m}$ is defined as:

$$
\sigma_{m}=\frac{\partial\left(X_{i} / X_{j}\right)}{\partial\left(W_{i} / w_{j}\right)} \cdot \frac{W_{i} / W_{j}}{X_{i} / X_{j}}
$$

Letting lower case letters represent the ratios for two different labour groups we have:

$$
\sigma_{m}=\frac{\partial x}{\partial w} \frac{w}{x}
$$

This, however, can be rewritten

$$
\sigma_{m}=\frac{\partial x}{\partial f} \cdot \frac{f}{x} \cdot \frac{\partial f}{\partial w} \frac{w}{f}=\sigma \cdot \sigma_{f w}
$$

which shows that the measured elasticity of substitution is equal to the true elasticity $\sigma$ (which is of course independent of wages) multiplied by the elasticity of marginal products with respect to wages $\sigma_{f w}$. The latter measures whether marginal products change when wages change. Since in almost all practical applications we are interested in $\sigma_{m}$, it makes little difference that we may not be able to separate the impact of $\sigma$ and $\sigma_{f w}$ on $\sigma_{m}$.

5 The estimation of $\sigma_{m}$, which need not be a constant, would be based on an alternative theory of labour demand. For instance, employers may undertake search costs to find cheaper inputs when the price of one factor increases. This implies that factor intensities may depend on relative factor prices. Developing such alternative theories of labour demand is, however, beyond the scope of this paper. 
Third, consider the large body of research on the slowdown in productivity growth in developed countries (see Denison (1979) among many others). One would think that this research would be highly dependent on the marginal productivity theory. As a matter of fact it is not. Almost all work focuses on average, not marginal, productivity which is much more easily measured. Rejection of the marginal productivity theory would not stop this useful applied research.

Finally, marginal productivity would seem not to be necessary in inputoutput analysis as developed by Leontief (1966). Input-output relations may be said to constitute 'recipes' to produce a given product output with the aid of inputs of varying character: inputs of other goods (raw materials, semi-finished products), equipment services and other production factors (types of labour). The method has proved very useful for the estimation of production increases in other industries than the one considered given or the joint production needed to attain a given set of final demand quantities desired (where final demand equals the total of consumption, investment and exports, all specified in terms of a given list of products). Later it has been enriched by the introduction of the concept of tradable and nontradable goods and has given rise to the 'semi-input-output method' (Kuyvenhoven, 1978). It should be recognized, though, that input-output theory has been developed also in the direction of substitutability between inputs (McFadden, Diewert, Kreyger (1978), De Boer (1981), for some quotations $c f$. the latter two).

All this does not exclude, however, that the marginal productivity theory may once be convincingly rejected. This would have important sociopolitical implications.

\section{REFERENCES}

Appelbaum, E. (1974), 'Tests in Production Theory', Working Paper No. 4, Summer Workshop, Department of Economics, University of British Columbia.

Boon, G.K. (1964), Economic Choice of Human and Physical Factors in Production, Amsterdam.

- (1978), Technology and Sector Choice in Economic Development, Alphen aan den Rijn.

__ (1980), Technology and Employment in Footwear Manufacturing, Alphen aan den Rijn/Germantown, MD.

- (1981), Technology Transfer in Fibres, Textile and Apparel, Alphen aan den Rijn/Rockville, MD.

Boer, P.M.C. de (1981), Price Effects in Input-Output Relations: A Theoretical and Empirical Study for the Netherlands, 1949-1967, Utrecht.

Denison, E.F. (1979), Accounting for Slower Economic Growth, Washington, DC and previous publications. 
Douglas, P.H. (1934), The Theory of Wages, New York.

Gottschalk, P.T. (1978), 'A Comparison of Marginal Productivity and Earnings by Occupation,' Industrial and Labor Relations Review, 31 (No. 3, April), pp. 368-378. Griliches, Z. and V. Ringstad (1971), Economies of Scale and the Form of the Production Function, Amsterdam-London.

Hamermesh, D.S. (1976), 'Econometric Studies of Labor Demand and Their Application to Policy Analysis,' Journal of Human Resources, 11, pp. 507-25.

Hamermesh, D.S. and J. Grant (1980), 'Econometric Studies of Labor - Labor Substitution and Their Implications for Policy,' Journal of Human Resources, 14, pp. 518-42.

Hildebrand, G. and T.C. Liu (1965), Manufacturing Production Functions in the United States 1957: An Interindustry and Interstate Comparison of Productivity, Ithaca, N.Y.

Kreyger, R.G. (1978), Production Functions and Interindustry Analysis, Ph.D. dissertation, University of Amsterdam.

Kuipers, S.K. (1974), 'On the Estimation of Short Run and Long Run Production Equations,' in: F.-L. Altmann et al. (eds.), On the Measurement of Factor Productivities, Papers and Proceedings of the 2nd Reisensburg Symposium, June 23-27, pp. 182-211, Göttingen.

Kuyvenhoven, A. (1978), Planning with the Semi-Input-Output Method, Leiden/Boston/ London.

Leontief, W. (1966), Input-Output Economics, New York.

Littlechild, S.C. (1981), 'Misleading Calculations of the Social Costs of Monopoly Power,' Economic Journal, 91, pp. 348-363.

Thurow, L. (1968), 'Disequilibrium and the Marginal Productivity of Capital and Labor,' Review of Economics and Statistics, 50 (No. 1 Feb.), pp. 23-31.

Tinbergen, J. and J. Kol (1980), 'Market-determined and Residual Incomes - Some Dilemmas,' Economie Appliquée, XXXIII, No. 2, pp. 285-301.

Tinbergen, J. (1980), 'Fonctions de production contenant plusieurs catégories de travail,' Cahiers du Département d'Econométrie, Faculté des Sciences Economiques et Sociales, Université de Genève.

Tinbergen, J. (1981), 'Contraproduktie,' in: P.J. Eijgelshoven and L.J. van Gemerden (eds.), Inkomensverdeling en openbare financien, Opstellen voor Jan Pen (Dutch), Utrecht/Antwerp, pp. 288-297.

\section{Summary}

\section{METHODOLOGICAL ISSUES IN TESTING THE MARGINAL PRODUCTIVITY THEORY}

Previous tests of the marginal productivity theory have been criticized on several grounds reviewed by the authors. One important deficiency has been the small number of factor inputs entered in the production functions. In 1978 Gottschalk suggested a method to estimate production functions with many inputs by assuming that the production process can be split into subprocesses. This reduces the probability of multicollinearity. The authors show that the method depends on an additional assumption. Tinbergen has developed a method for avoiding this assumption. Its application to American cross-section (state) data did not alter the estimated coefficients greatly. 